\title{
IMPLEMENT ALGORITHM TO REDUCE EFFECT OF SNOWY WEATHER IN NORTH OF IRAQ ON FSO SIGNAL
}

\author{
Hashem A. jabar a, *, Rashid A. Fayadh ${ }^{\text {a }}$ \\ ${ }^{a}$ Faculty of Engineer, Middle Technique University, College of Electric and Electronic Engineer, Baghdad, Iraq- \\ (hashem.jabar@yahoo.com)
}

\begin{abstract}
:
Free space optic (FSO) is now a well-established access technology that commonly start using in wireless data transmission because of its large advantage like cost effective and Line-Of-Sight (LOS) permission which lead this technology to be more secure and get own to everyone. While radio frequency (RF) travels using optical fiber through weather atmospheric, large phenomena like (Rain-fog/haze-snow and temperature) works to block laser beam from reaching its receiver. Optical code division multiple access (OCDMA) is a hot topic due to its large advantage such as permitting large number of user to transmit large amount of data using single optical laser beam, but multiple users share single laser beam lead to increase multiple access interference (MAI) which primary deteriorates the performance of OCDMA. Sub-Carrier Multiplexing (SCM) is used in the system to multiplex multiple data stream on single laser beam. Spectral Amplitude Coding (SAC) technique used to enhance FSO signal by allocate own spectrum to each user, this technique generate code called Multi-Diagonal (MD) code that allow zero interaction between user data. This paper focused on the effect of snowy weather in north of Iraq on the FSO signal by using (SCM-SAC-OCDMA) based on multi-diagonal code and determined the distance between the transverse with approach bit error rate (BER) in the receiver side. Based on the system result data can travel through [0.4 - 4] Km as transmission distance under different snow rate with BER between $\left[10^{-12}-10^{-8}\right]$.
\end{abstract}

KEYWORDS: FSO/ RF, SCM-SAC-OCDMA, Multi Diagonal code, BER.

\section{INTRODUCTION}

FSO has offered service providers with viable alternative or complement to fiber optic for optical connectivity. FSO bring lower cost, higher bandwidth, secure system, flexibility, full duplex operation which mean that information can be transmitted and received in parallel at the same time ( Baksheesh S, et al, 2002). FSO technology in terrestrial application depends on the propagation of the laser beam through the troposphere, in this weather layer many phenomena's occur which lead to effect on the FSO system performance (Stamation V.K, 2011). Therefore, it is necessary to study the effect of climate for FSO because free space is the channel between transmitter and receiver (Amanpreet K, et al, 2015).FSO system built using SCM-SAC-OCDMA based on MD code and intermediate stage called "

Optical Amplifier". OCDMA network needs fewer devices than other network and its equipment is simple, lower cost and can implement high-speed transmission (David J.R, et al, 2015). SCM is attractive choice in the system for high speed optical data transmission because it does not need very high speed electronic device, SCM can handle the high speed electronic signal ( Tai-hoon K, et al, 2011). Optical amplifier used in the system to compensate the losses on the signal power when travel through turbulence weather. Type of code that generate in the system while using SAC technique called Multi-Diagonal (MD) code, it is used in the system to neglect the Multiple Access Interference (MAI) that may generated in the system because of multiple users that share the same single laser beam , the main reason to used MD code rather than Diagonal Double weight (DDW) code or Random
Diagonal code (RD) because it is the only code in FSO concept than ensure zero probability of correlation. In this paper the effect of snowy weather in north of Iraq on FSO system has been taken and all the technique that used in the proposed SCMSAC-OCDMA system are built using " opt system " software Ver.7 to get BER result in the receiver sides and notice signal behavior under snow weather.

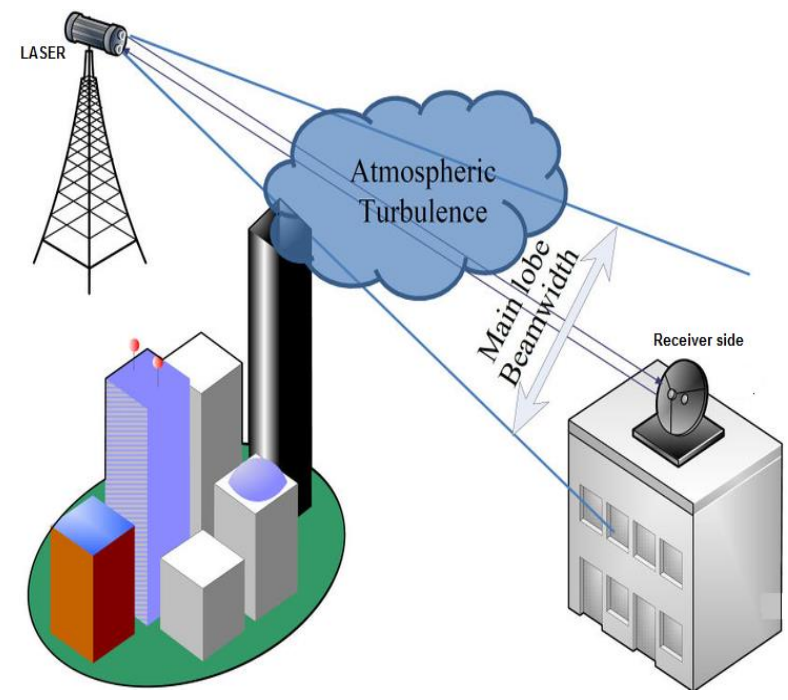

Figure 1. FSO concept that connect two stations.

\footnotetext{
* Corresponding author

This is an open access under a CC BY-NC-SA 4.0 license (https://creativecommons.org/licenses/by-nc-sa/4.0/)
} 


\section{MATHEMATICAL MODEL OF SNOW WEATHER ATTENUATIONS:}

Snow weather state is the largest phenomena that effect on the signal performance because of the largest snowball that is larger than rain and haze particles. Attenuation due to snow can vary depending upon the snowflake size and snowfall rate. Snowflake size can be large as $20 \mathrm{~mm}$, which can completely block the transmission path of the optical laser beam. Attenuation can be classified into dry and wet snow attenuation. The specific attenuation $(\mathrm{dB} \backslash \mathrm{km})$ of the two type of snow is given by following equation ( Subrat K.V, et al, 2017) (Otto S, et al, 2016).

$\beta_{\text {snow }}=a S^{b}$

Where $\mathrm{S}$ is snow rate in $(\mathrm{mm} / \mathrm{hr})$

Values of $\mathrm{a}$ and $\mathrm{b}$ in dry and wet snow are given by:

Dry snow: $\mathrm{a}=5.42 \times 10^{-5}+5.4958776, \mathrm{~b}=1.38$

Wet snow: $1.023 \times 10^{-4}+3.7855466, \mathrm{~b}=0.72$

The snow attenuation based on visibility range $\mathrm{V}$ can be calculated using the following model:

$\propto_{\text {snow }}=\frac{58}{V}$

Where $\mathbf{V}$ is visibility range in $\mathrm{km}$.

Table 1. Snow Quantity (mmlhr) in Three Regions in North of Iraq

\begin{tabular}{|l|c|c|c|c|}
\hline Region & Jan. & Feb. & Nov. & Dec. \\
\hline Erbil & 20 & 0 & 0 & 0 \\
\hline Sulaymanya & 25 & 5 & 0 & 0 \\
\hline Duhuk & 25 & 10 & 0 & 15 \\
\hline
\end{tabular}

Table 2. Visibility in Range (km/hr) in Two Region in North of Iraq

\begin{tabular}{|c|c|c|c|c|c|c|}
\hline $\mathbf{R}$ & $\mathbf{1}$ & $\mathbf{2}$ & $\mathbf{3}$ & $\mathbf{1 0}$ & $\mathbf{1 1}$ & $\mathbf{1 2}$ \\
\hline Kirkuk & $\underline{3.1}$ & 4 & 6 & 8 & 7 & $\underline{300 \mathrm{~m}}$ \\
\hline Mosul & $\underline{200 \mathrm{~m}}$ & 6 & 3 & 2 & 3 & 1.5 \\
\hline
\end{tabular}

*highlight numbers mean snow weather falls in that time.

Table 3. Snow Weather Attenuation Value in ( $\mathrm{dB} \backslash \mathrm{km})$ Using Eq.

\begin{tabular}{|c|c|c|c|}
\hline Region & $\begin{array}{c}\text { Max snow } \\
\text { falling } \\
\text { (mm/hr) }\end{array}$ & $\begin{array}{c}\text { Attenuation } \\
\text { value in dry } \\
\text { snow weather }\end{array}$ & $\begin{array}{c}\text { Attenuation } \\
\text { value in wet } \\
\text { snow weather }\end{array}$ \\
\hline Erbil & 20 & $343 \mathrm{~dB} / \mathrm{km}$ & 32.725 \\
\hline Sulaymanya & 25 & $400 \mathrm{~dB} / \mathrm{km}$ & 38.428 \\
\hline Duhuk & 25 & $400 \mathrm{~dB} / \mathrm{Km}$ & 38.428 \\
\hline
\end{tabular}

According to table 3, the dry snow attenuation is larger than wet snow (Attenuation reach to $400 \mathrm{~dB}$ in dry state), the reason is because dry snowball stay long time in free space until reach to ground, thus lead to large attenuate the optical wireless beam.
Table 4. Snow Weather Attenuation Value in $(\mathrm{dB} \backslash \mathrm{km})$ Using Eq. (4)

\begin{tabular}{|l|c|c|}
\hline \multicolumn{1}{|c|}{ Region } & $\begin{array}{c}\text { Visibility through } \\
\text { snow weather }\end{array}$ & $\begin{array}{c}\text { Attenuation value } \\
(\mathbf{d B} / \mathbf{k m})\end{array}$ \\
\hline Kirkuk & $3.1 \mathrm{~km}$ & 18.70 \\
\hline Mosul & $200 \mathrm{~m}$ & 290 \\
\hline
\end{tabular}

\section{PROPOSED SCM-SAC-OCDMA SYSTEM WITH OPTICAL AMPLIFIER}

Figure 2 shows the proposed system of FSO system with 6 users $\left(4 \lambda^{*} 1 \mathrm{Gbps}\right)$ which is built using "opts system" software ver. 7. In the transmission side, each users data represent by (random bit generator, Non-Return to Zero (NRZ) coding, sine wave generator with different frequency, see table5), this three blocks represent the form of SCM technique. SCM used in the system for transmission multiple signals using single optical transmission beam, this reduce the cost of the system since each user does not required an optical transmission laser ( Rajiv R, et al, 2009). Since there is multiple user share the same optical link, it suffers to Multiple Access Interference (MAI). MAI work with the external weather effect to reduce signal quality and increase BER in the receiver side, so, SAC is one of the coding technique that reduce MAI by allocate own spectrum to each user in the system and then combine them using Wavelength Division Multiplexing (WDM) , then initiate transmission towards the receiver (Nitin A, et al, 2014). MD code used in the system because it is simple in design and allow support large number of users with high data rate. Optical amplifier (OA) which is type of Erbium Doped Fiber Amplifier (EDFA) used to perform the amplification of optical intensity direct in the optical domain without resorting to any electricdomain regeneration, the reason of using EDFA because it does not require extra device in the system design to complete the amplification process (Stephano B, 2014). In the transmission side and in order to modulate the laser light with users data, an external optical modulator has been used in the system called Mach-Zehnder modulator (MZM). The reason of using this type of modulator because it deals with lights (multiply the light with the bits). In the receiver side, the de-multiplexing technique used to decode the received signal and then each code is filtered by using light filter called Fiber Bragg Grating (FBG) filter, this filter decoding MD code by pass the required spectrum and neglect the other spectrum that multiplied together in single unguided link. The light spectrum then passed to the Photo Detector (PD) that collect the light and convert to electric signal. To retrieve the original sending data, a local microwave frequency is mix electrically with the incoming signal, and filtered using low pass filter (LPF). System result notes from blocks (Eye Diagram ) which indicate BER value in receiving side and show eye diagram figure (figure that express signal behavior in atmospheric layer). Table 5 shows the values for each component that used to complete the system design. Finally, some extra component used to complete the system like signal multiplier, signal adder, data analyzer, signal meter. 


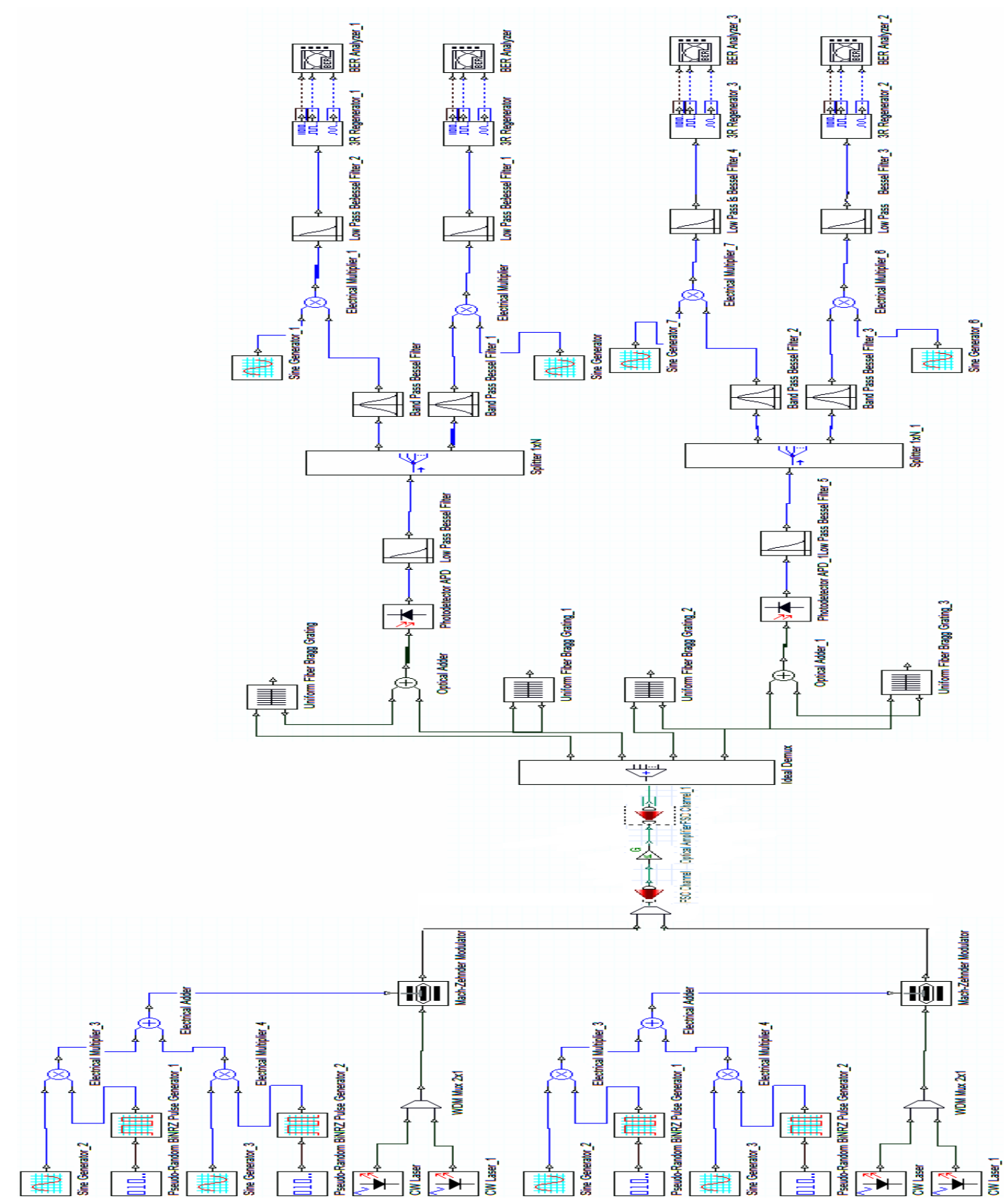

Figure 2. Proposed SCM-SAC-OCDMA with optical amplifier based on MD code.

Table 5. Parameters Used in System Design

\begin{tabular}{|c|c|}
\hline parameter & descriptions \\
\hline Wavelength & $1550 \mathrm{~nm}$ \\
\hline $\begin{array}{c}\text { Transmission optical } \\
\text { power }\end{array}$ & $25 \mathrm{~dB}$ \\
\hline Optical amplifier gain & 75 \\
\hline Transmission technology & CW laser \\
\hline Modulation type & Mach-Zehender \\
\hline Photo-detector & APD \\
\hline $\begin{array}{c}\text { Transmission aperture } \\
\text { diameter }\end{array}$ & $5 \mathrm{~cm}$ \\
\hline Receiver aperture diameter & $20 \mathrm{~cm}$ \\
\hline ADP Gain & 10 \\
\hline System bandwidth & $500 \mathrm{Gbps}$ \\
\hline Sine wave frequency & $0.6 \mathrm{Mhz}, 32 \mathrm{Ghz}, 1 \mathrm{Thz}$ \\
\hline User bit rate & $1 \mathrm{Gbps}$ \\
\hline
\end{tabular}

\section{SYSTEM RESULT AND DISCUSSION:}

To get the result of the proposed SCM-SAC-OCDMA system, attenuation value in table (3) \& (4) and parameter in table (5) are used in the software system to get the system result. Table (6) show the approach BER that system can tolerate when propagate laser beam through free space and much distance can be covered when handle data for 4 users under different snow rate in 6 different regions in north of Iraq:

Table 6. System Results in Different Region

\begin{tabular}{|l|c|c|c|}
\hline \multicolumn{1}{|c|}{ Region } & $\begin{array}{c}\text { Max distance } \\
\text { system can } \\
\text { tolerate }\end{array}$ & $\begin{array}{c}\text { BER in Dry } \\
\text { snow }\end{array}$ & $\begin{array}{c}\text { BER in } \\
\text { Wet snow }\end{array}$ \\
\hline Mosul & $4 \mathrm{~km}$ & \multicolumn{2}{|c|}{$4 * 10^{-12}$} \\
\hline Kirkuk & $0.4 \mathrm{~km}$ & \multicolumn{2}{|c|}{$2^{*} 10^{-8}$} \\
\hline Erbil & $0.34 \mathrm{~km}$ in Dry & $1 * 10^{-9}$ & $2 * 10^{-8}$ \\
& $\begin{array}{l} \\
\text { snow }\end{array}$ & \\
& $1.95 \mathrm{~km}$ in wet & & \\
& snow & & \\
\hline
\end{tabular}




\begin{tabular}{|c|c|c|c|}
\hline Sulaymania & $\begin{array}{l}0.3 \mathrm{~km} \text { in Dry } \\
\text { snow } \\
1.9 \mathrm{~km} \text { in wet } \\
\text { snow }\end{array}$ & $1 * 10^{-10}$ & $3 * 10^{-8}$ \\
\hline Duhok & $\begin{array}{l}0.3 \mathrm{~km} \text { in Dry } \\
\text { snow } \\
1.95 \mathrm{~km} \text { in wet } \\
\text { snow }\end{array}$ & $1 * 10^{-10}$ & $3 * 10^{-8}$ \\
\hline
\end{tabular}

In the table above, BER reach to $10^{-8}$ in maximum snow falling and this value decrease when snow falling decrease because the external influence on the signal decrease.

Figure (3) show that the dry snow largely effects on system performance and attenuate the signal laser beam more than wet snow (dry snow attenuation reaches to $400 \mathrm{~dB}$ and in wet snow reach to $38 \mathrm{~dB}$ only). The reason because dry snow is fluffy and stay longer time in free space when falling unlike wet snow which fall down faster than dry snow and not largely block laser beam when travel in free space .

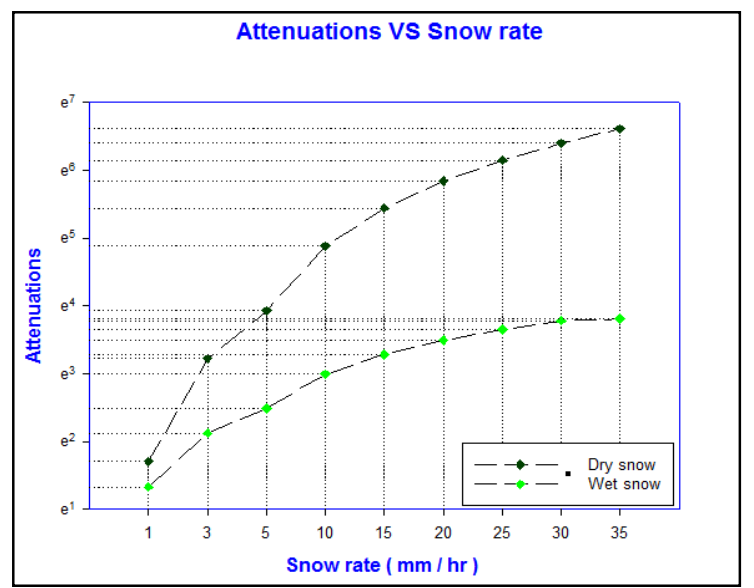

Figure 3. Show the attenuation rate in dry and wet snow

Figure (4) shows the enhancement that the optical amplifier (OA) added to the system by compensate the power losses due to signal effected by the atmosphere turbulence. The optical amplifier with gain between (1-100) can amplify the signal according to the gain that used in table (5). It can be seen when using optical amplifier, the BER decrease in dry and wet snow because of adding more power to the laser beam and thus leads to enhance the system and permit signal beam to cover long distance with high laser power and minimum BER in reception sides. The OA that proposed in this system does not require electric and optical converter, this leads the system not to consume more cost and time to installation.

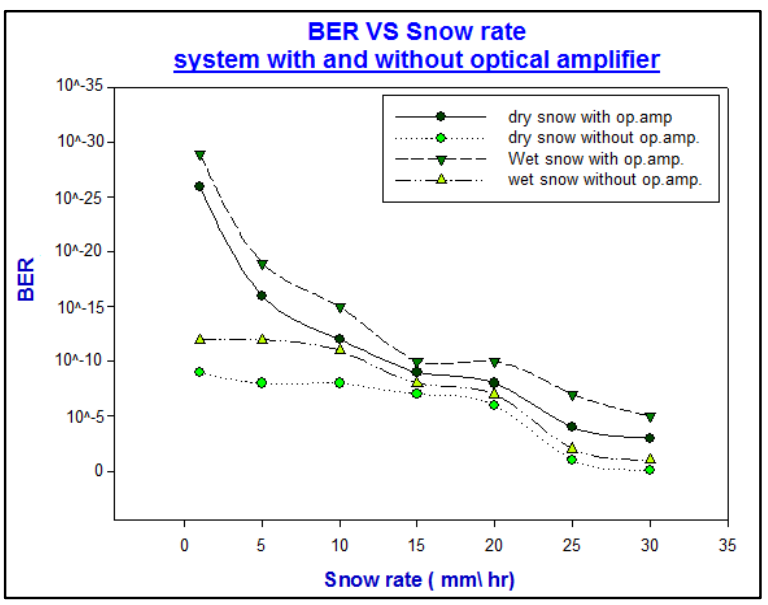

Figure 4. Show BER in two-snow type and the enhancement after using OA.
Figure $(5,6,7,8)$ shows the eye diagrams status of the four region in north of Iraq, the eyes is figures that look like the opening of an eyes and shows the common indicator of the quality of signal in high speed digital transmission of each region in north of Iraq. It can be seen that the region that has heavy snowfall leads to increase BER, so the eye diagram will be in unstable state and contain large rubbish lines because of large affected by multiple access interference ( snow particles) when signal travelling through air and have untidy line because of largely effected by free space particles.

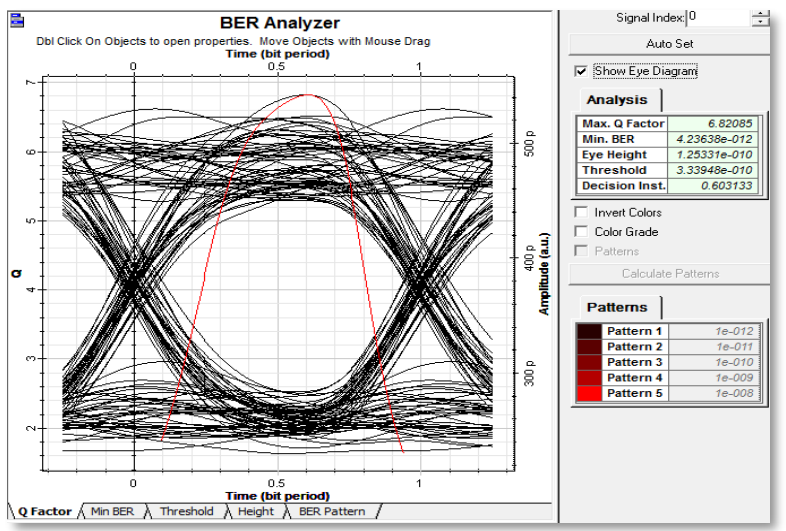

Figure 5. Eye diagram of Kirkuk where the attenuation is $18.7 \mathrm{~dB} / \mathrm{km}$

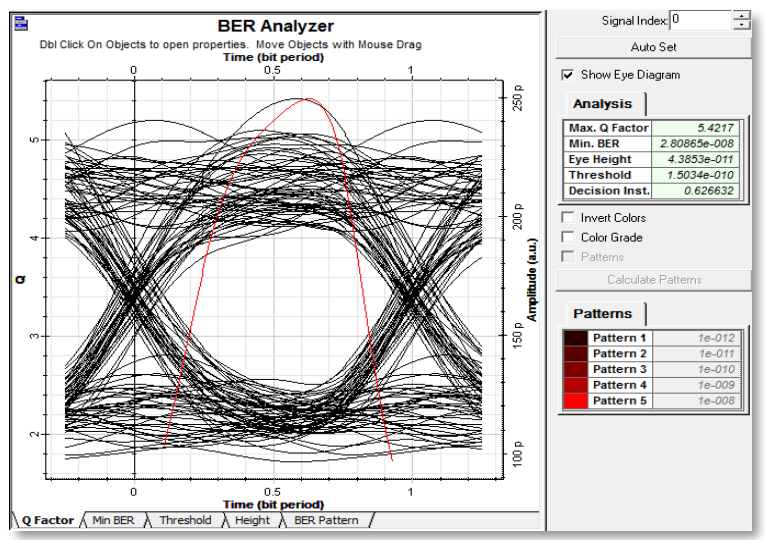

Figure 6. Eye Diagram of MOSUL Where the Attenuation is $290 \mathrm{~dB} / \mathrm{km}$

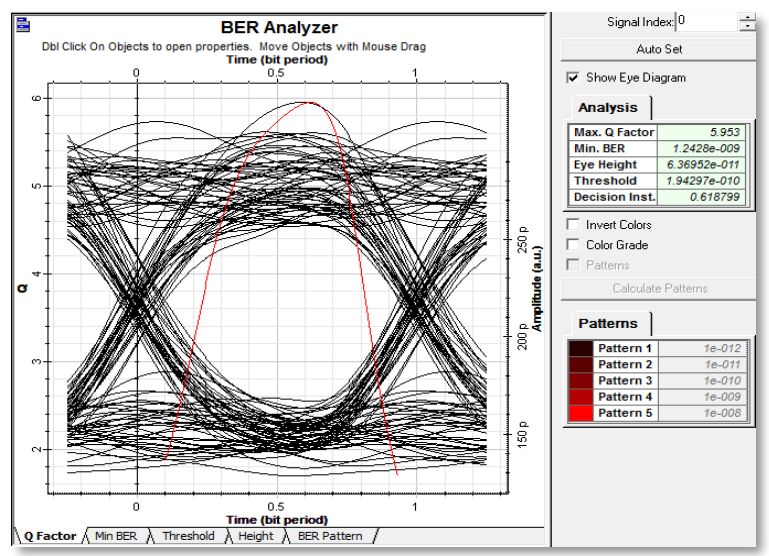

Figure 7. Eye Diagram of ERBIL Where the Attenuation is $343 \mathrm{~dB} / \mathrm{km}$ 


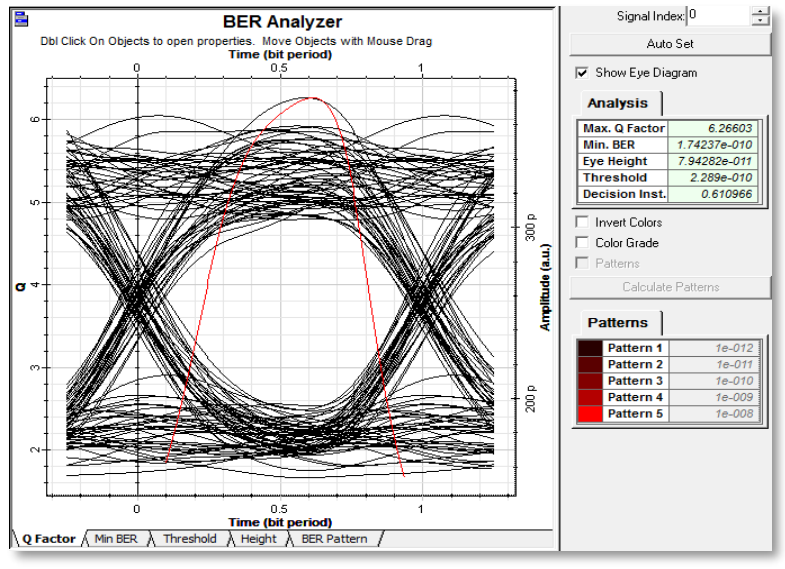

Figure 8. Eye Diagram of SULAYMANIA Where the Attenuation is $400 \mathrm{~dB} / \mathrm{km}$

To get more result from the system software and notice the signal behaviors, Spectrum analysis of the proposed system shows the large effect of atmosphere phenomena on the laser performance, it absorbs the photons energy (power) when signal cut through snow weather and hence leads to increase in system degradation. Figure $(9,10)$ shows how the laser spectrum can be affected by free space phenomena. Figure 9 show the signals spectrum before transmission, the system power range reach to $-18 \mathrm{dBm}$, but in figure 10 the system power range reach to $-22 \mathrm{dBm}$.

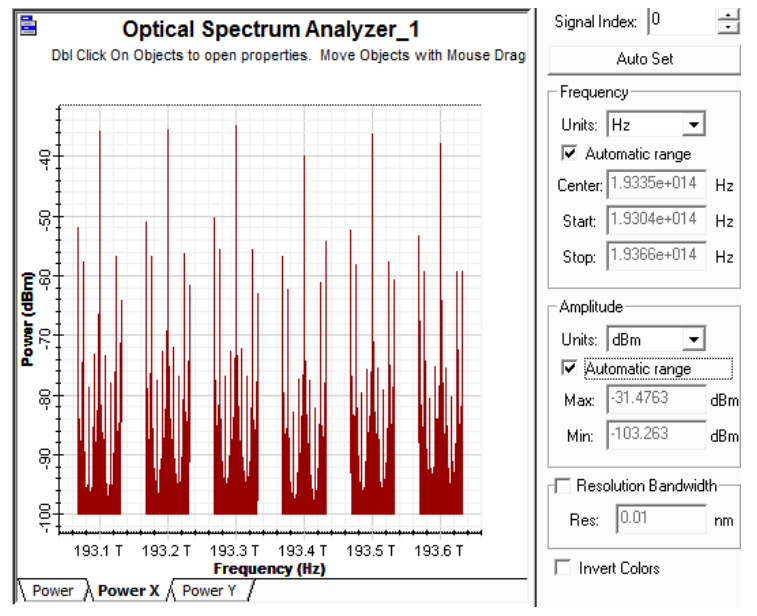

Figure 9. show the optical spectrum before signal transmission

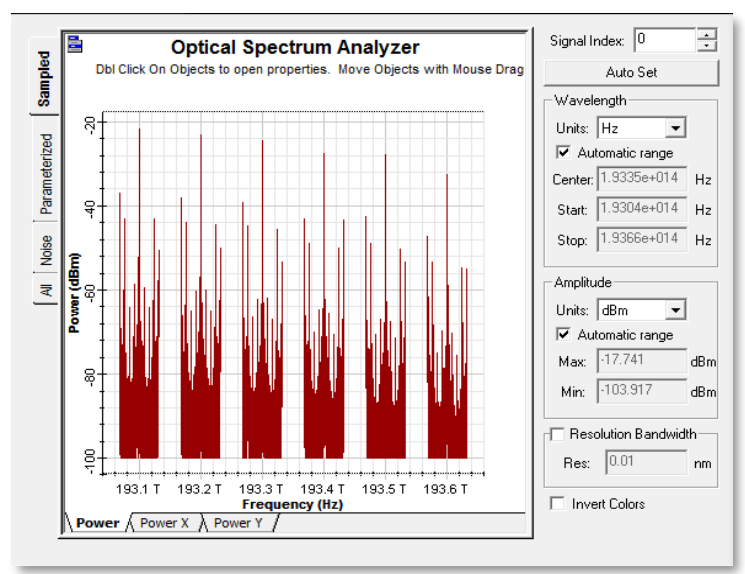

Figure 10. Show the optical spectrum after affected by snow weather.

\section{DISCUSSIONS}

This paper analysis the effect of snow phenomena in north of Iraq region on FSO system performance. Snow weather state is the highest effect on the FSO signal; its attenuation can reach to $400 \mathrm{~dB}$ under storm rain and dry snow occurs because it is effect on the signal larger than wet snow, so it can completely block the transmission path and scattered the laser beam. The scattering phenomen allow the receiver aperture diameter not able to collect the entire transmission data rate, hence leads to increase BER in the receiver sides. A simple model that proposed to predict optical attenuations by using SCM-SAC-OCDMA system with intermediate stage 'optical amplifier' based on MD code. Optical amplifier and all the technique that system used it is to decrease BER in receiving side, allow the signal to reduce the external noise that signal correlate with it in free space and try to permit the laser to cover large distance without large missing of signal power. MD code used in system to add more simplicity in system design and neglect MAI that is generate due to multi user sharing single laser beam, MD code have best characteristics than other codes in FSO. Result of this new system show that snow has large effect on signal because of its large particles $(20 \mathrm{~mm})$, so maximum transmission distance is $(4 \mathrm{~km})$ in Kirkuk and minimum distance is $(0.3 \mathrm{~km})$ in Sulaymania and Duhuk in dry snow weather state . As for the BER, they ranged between $\left(10^{-12}-10^{-8}\right)$ and the maximum attenuation value records $400 \mathrm{~dB}$.

\section{REFERENCES}

Baksheesh S.Ghuman, Heinz wiillebrand, "Enabiling Optical connectivity in today's network", SAMS publishing, p.p.3-22, 2002

Stamation V. Kartalopoulos,"Free space optical network for ultrabroad band services", john Wiley \& sons publishing, p.p.31-52, 2011.

Amanpreet Kaurand, Gurinder singh, "performance comparison of various detection technique for SCM-OCDMA system using DW and MDW code, paper of IEEE journal, 2015.

David J.Richardson, Hongxi yin,' 'optical code division multiple access communication networks", Springer science \& business media publishing, p.p.20-24, 2009

Tai-hoon kim, Hojjat Adeli, Dominik Slezak, Kyo-il chung, "Future Generaion Information Technology", "High speed optical coherent transmission system using narrowband FM subcarrier multiplexing", springer science publishing, p.p.100-105, 2011.

Subrat Kar,V.K.Jain, Hemani Kaushal, "free space optical communication", Springer science publishing,p.p.5055,2017 .

Otto Strobel, " optical and microwave technologies for telecommunication network ", John Wiley \& Sons publishing, p.p. 351, 2016.

Rajiv Ramaswami ,Kumar N Sivaraian ,Gaen H.S, optical network / apractical perspective, published by morgan Kaufmann \& springer science, Vol. 3 , p.p.251-253, 2009 .

Nitin Afzalpulkar, Vishun Srivastave, Ghonshyam singh, Deepak Bhatnagar," proceeding of the international conference on recent cognizance in wireless communication system and image processing", Design and analysis of different decoders for SAC-OCDMA system, springer science publishing, p.p.427-434, 2014.

Stephano Bottacchi, "Theory and design of terabit optical fiber transmission system", Cambridge university press publishing, p.p. 290-292, 2014 